\title{
Comparative Gas Chromatographic-Mass Spectrometric Evaluation of Hop (Humulus lupulus L.) Essential Oils and Extracts Obtained Using Different Sample Preparation Methods
}

\author{
Magdalena Ligor • Mantas Stankevičius • Anna Wenda-Piesik • \\ Kẹstutis Obelevičius • Ona Ragažinskienė • Žydrūnas Stanius • \\ Audrius Maruška $\cdot$ Boguslaw Buszewski
}

Received: 13 June 2013 / Accepted: 18 November 2013 /Published online: 11 December 2013

C The Author(s) 2013. This article is published with open access at Springerlink.com

\begin{abstract}
The main aim of investigations was to identify chemotypes and determine differences between some domestic hop varieties and wild hops, which were collected from some regions of Lithuania and cultivated at the same edafoclimatic conditions in hops collection of Kaunas Botanical Garden of Vytautas Magnus University. One of objectives was to compare essential oils of hops (2 years harvest) by the evaluation of volatiles content. Among the main components of hop essential oils monoterpenes ( $\beta$-myrcene) and sesquiterpenes ( $\alpha$-humulene and $\beta$-caryophyllene) were determined using gas chromatography coupled with mass spectrometry (GC-MS). Retention parameters $\left(t_{\mathrm{R}}\right.$, calculated retention index, and Kovats retention index) and $m / z$ value of molecular ion for selected compounds from hop essential oils were determined. Samples were prepared by applying solid phase microextraction (SPME), supercritical fluid extraction (SFE)
\end{abstract}

\footnotetext{
M. Ligor $\cdot$ B. Buszewski $(\bowtie)$

Department of Environmental Chemistry and Bioanalytics,

Faculty of Chemistry, Nicolaus Copernicus University,

7 Gagarina Street, 87-100 Toruń, Poland

e-mail: bbusz@chem.umk.pl

M. Stankevičius $\cdot$ Ž. Stanius $\cdot$ A. Maruška

Department of Biochemistry and Biotechnologies,

Faculty of Natural Sciences, Vytautas Magnus University, Vileikos 8,

44404 Kaunas, Lithuania
}

\author{
A. Wenda-Piesik \\ Department of Plant Growth Principles and Experimental \\ Methodology, University of Technology and Life Sciences, \\ 20 Kordeckiego Street, 85-225 Bydgoszcz, Poland \\ K. Obelevičius $\cdot$ O. Ragažinskienė \\ Kaunas Botanical Garden of Vytautas Magnus University, \\ Ž.E. Žilibero 6, 46324 Kaunas, Lithuania
}

and accelerated solvent extraction (ASE). The steam distillation was used to obtain hop essential oils. The chemometric comparison of domestic and wild hops based on GC-MS analysis data was carried out. The obtained statistical results allow us to classify the investigated wild forms and domestic varieties of hops according to the similarities of their chemotypes. The concentration of $\beta$-myrcene, $\alpha$-humulene in hop essential oils obtained from cones 2 years harvests is much higher than other volatile organic compounds (15.2$23.7 \%$ in total contribution). In analysed essential oils $\beta$ farnesene is a constituent in higher quantity of hop essential oils obtained from cones from second time harvest than from cones from first harvest. This can be explained by the year-toyear vegetation conditions difference.

Keywords Hop (Humulus lupulus L, family Cannabaceae Endl.) · Extraction methods · Essential oils · GC-MS ·

Chemometric methods

\section{Introduction}

It is commonly known, that hop cones were used in brewery for centuries, because of their aroma and provided bitterness (Zanoli and Zavatti 2008). Each variety of hops has its own typical essential oil pattern which is an important tool for the determination of hop chemotypes, ecotypes or evaluation of hop quality (Katsiotis et al. 1990).

There are many forms of wild hops, which are similar according to their composition, so it is very difficult to distinguish between various ecotypes or phenotypes. In 1926, a collection of hops was created at the Kaunas Botanical Garden of Vytautas Magnus University by K. Grybauskas, where 
many wild forms and different varieties from Western and Central Europe were collected for scientific investigations and nurturing of new varieties. Hybridization between the climate and plant illness resistant wild forms and highly productive, but less resistant domestic varieties was carried out. Based on that, five new Lithuanian hop varieties were nurtured (Obelevičius 2003). Combination of modern instrumental analysis and chemometric methods provides a possibility to classify various chemotypes of plants, revealing differences of chemical composition of their secondary metabolites. Unique situation, when plants have been cultivated at the same collection (identic edafoclimatic conditions), provides a possibility to focus exclusively on the genetically resulted chemotyping, whereas comparison of several harvests shows the influence of hydrothermal conditions variation on the biosynthesis of secondary metabolites in plants. Over 170-200 compounds can be separated and their quantities estimated using capillary $\mathrm{GC}$ analysis of hops essential oils in one run, which is a very suitable tool performing comparative study of different plants by so called chromatographic profiling or fingerprinting (Stankevičius et al. 2007). Evaluation of those results by chemometric methods not only reveals the information analogous to that obtained in genetic analysis, but provides phytochemical composition data, which are indispensible for standardization and quality control of plant raw materials required in food or pharmaceutical industry. High resolution and ability to provide precise and accurate qualitative and quantitative data distinguishes GC-MS analysis as valuable tool for taxonomic studies of plants.

For the identification of hop varieties and determination of aroma properties hop cones essential oils have been analysed (Katsiotis et al. 1990; Kovačevič and Kač 2001, 2002). Several studies were devoted to analysis of essential oils of wild hops growing in Eastern Lithuania (Mockute et al. 2008; Bernotiene et al. 2004). Studies revealed the complexity of the essential oils composition determined in the investigated samples. In one of them wild hop cones were collected in 12 different localities of Eastern Lithuania and 120 compounds were identified in the essential oils (Mockute et al. 2008). $\alpha$-Humulene (11.1$33.4 \%)$ dominated in seven oils, myrcene (15.7-21.1\%) in four oil samples and $\gamma$-elemene (14\%) in one oil. The other higher concentration constituents of the essential oils were $\alpha$ humulene (14.2-16.2\%), myrcene (7.7-19.3\%), $\beta$ caryophyllene $(7.6-14.5 \%),(E)-\beta$-farnesene $(7.8-10.4 \%)$, $\gamma$-curcumene $(15.8 \%)$, ar-curcumene $(10.4 \%)$, zingiberene (8.4\%) and $\beta$-bisabolol (11.8-13.5\%). In other study five hops samples were investigated. In the essential oils, 98 compounds were identified. The compounds with humulene, bisabolene, caryophyllene farnesene and elemene skeletons in four samples comprised from $54.8 \%$ to $70.8 \%$ of the essential oils (Bernotiene et al. 2004).

In order to obtain hop essential oil, the steam distillation method is commonly used (Kovačevič and Kač 2001; Howard
1970). This method requires a relatively large amount of sample (50-100 g) and it is rather time consuming. The procedure takes ca. $4 \mathrm{~h}$. Essential oils obtained by this method are ready to use for GC analysis after appropriate dilution without additional purification. Currently, extraction methods such as supercritical fluid extraction (SFE) and solid phase microextraction (SPME) are successfully applied for the characterisation of hops and other plants raw material aromatic properties (Kovačevič and Kač 2001; Ravenchon 1997; Ligor and Buszewski 1999; Ligor et al. 2000). Moreover, other extraction methods including solid-phase extraction (SPE) and solvent extraction are successfully used for the isolation of nonvolatile compounds from plant materials (Buszewski et al. 1993a; b; Ligor et al. 2008). SPE in off-line columns has become a popular and effective method of sample preparation, particularly for purification and/or isolation of polyphenolic compounds present in biological materials and natural products (Buszewski et al. 1993a,b). Next extraction method, accelerated solvent extraction (ASE) was successfully used for the extraction of bitter acids from hops and hop products (Čulík et al. 2009). SFE method is suitable for extraction of volatile and nonvolatile compounds of hops including essential oils and hops bitter acids (Langezaal et al. 1990; Dzingelevičius et al. 2011). The composition of extract obtained using supercritical $\mathrm{CO}_{2}$ is highly dependent on the temperature and pressure used for extraction. Higher recoveries of volatile compounds are obtained at lower temperatures and pressures of supercritical fluid whereas more bitter acids and resinous compounds are extracted at elevated pressures and temperatures. This method is routinely used for production of bitter acids extracts for beer brewing industry.

Various classes of chemical compounds are identified in hop extracts including terpenes, bitter acids, chalcones, flavonol glycosides (kaempferol, quercetin, rutin) and catechins (catechin gallate, epicatechin gallate) (Zanoli and Zavatti 2008; Sägesser and Deinzer 1996). The most important compounds of hop essential oils obtained from cones are monoterpenes (myrcene) and the sesquiterpenes including $\alpha$ humulene and $\beta$-caryophyllene (Zanoli and Zavatti 2008; Malizia et al. 1999; Eri et al. 2000). Bitter acids (5-20 \% of hop strobile weight), which are phloroglucinol derivatives, are non-volatile compounds and usually are classified as $\alpha$-acids and $\beta$-acids. Both groups contain a 3-,4-,5-, or 6-carbon oxoalkyl side chain: $\beta$-acids are structurally different from $\alpha$ acids for one more prenyl group. The bitter acids are present in hops as a complex mixture of variable composition and concentrations. The main $\alpha$-acids are humulone (35-70 \% of total $\alpha$-acids), cohumulone (20-65\%) and adhumulone (10$15 \%$ ); the corresponding $\beta$-acids are lupulone (30-55\% of total $\beta$-acids), colupulone and adlupulone (Zanoli and Zavatti 2008; Kornyšova et al. 2009).

It is well known, that environmental and biological data are usually characterized by high variability, because of a variety 
of natural and anthropogenic influences. The best approach to avoid misinterpretation of environmental and biological objects is the application of chemometric methods for classification and modeling (Kowalkowski, et al. 2006). The multidimensional data analysis methods are very popular in such studies dealing with measurements and monitoring (Bro et al. 2002; Munck et al. 1998).

Current work is focused on the separation and determination of volatile organic compounds in essential oils from different forms of wild hops cones and a few varieties of domestic hops cones cultivated at the same collection by means of gas chromatography coupled with mass spectrometry (GC-MS). Volatile compounds were isolated using extraction methods such as steam distillation, SPME, SFE, and ASE. The qualitative characterisation of analysed essential oil samples by GC-MS was performed. Chemometric methods were used for the clasification of obtained data.

\section{Materials and Methods}

\section{Sample Preparation}

During this study six samples of wild hop forms (tagged as Nos. 43, 47, 49, 52, and 64, which were registered at regional ex situ plants collection as V00041, V00052, V00054, V00056, V00068), naturally growing in Lithuania wilderness, and for comparative reasons other two samples of domestic varieties of hops (Alta and French Houblon precoce, which were deposited and registered at regional herbarium as V00019, V00022) were analysed. All samples of hop cones were obtained from the hop collection grown in the Kaunas Botanical Garden of Vytautas Magnus University. Also hop essential oils were obtained from hop cones two times harvest (2005 and 2006).

Essential oil of dry hop cones was isolated using SFE apparatus Hewlett Packard SFE 7680 T (Hewlett Packard, Palo Alto, CA, USA). Five hundred milligrams of sample was weighted for extraction using $\mathrm{CO}_{2}$ supercritical fluid as an extraction solvent (programmed temperature $50{ }^{\circ} \mathrm{C}$, pressure 91 bar, density $0.3 \mathrm{~g} / \mathrm{ml}$ ). The flow rate of $\mathrm{CO}_{2}$ was fixed at $1 \mathrm{ml} / \mathrm{min}$ and trap temperature at $25{ }^{\circ} \mathrm{C}$. Octadecylsilica trap was used to collect extracts obtained from hop cone matrices. All extraction processes were performed within $15 \mathrm{~min}$. Sample was desorbed from octadecylsilica trap with $0.7 \mathrm{ml}$ of $n$-heptane.

The steam distillation was the next sample preparation method used to obtain hop essential oil. The essential oils of various hop samples were isolated by steam distillation using a Clavenger apparatus. The experimental conditions were as follows: $30 \mathrm{~g}$ of dried and pulverized hop cones (ground in a mortar with pestle) were weighed into a 2,000-ml distillation flask. Next, the volume of deionised water $500 \mathrm{ml}$ was added, and the mixture was distilled for $3 \mathrm{~h}$. Obtained essential oils were collected from the condenser. Before GC-MS analysis, $2.5 \mu \mathrm{l}$ of essential oil obtained by steam distillation was diluted with $5 \mathrm{ml}$ of $n$-heptane.

Other extraction methods such as ASE and SPME were used. For ASE method $2.6 \mathrm{~g}$ of dry hop cones was taken. This method was developed by means of extractor ASE 100 (Dionex Co., Sunvale, CA, USA). Two steps of extraction were applied: first extraction — pressure $11 \pm 0.1 \mathrm{MPa}$, temperature $50 \pm 1{ }^{\circ} \mathrm{C}$, time $5 \mathrm{~min}$, organic solvent: hexane (45 ml); second extraction - pressure $11 \pm 0.1 \mathrm{MPa}$, temperature $50 \pm 1{ }^{\circ} \mathrm{C}$, time $5 \mathrm{~min}$, organic solvent: dichlorometane (45 ml). For GC-MS analysis, $1 \mu$ l of obtained extracts was taken.

Some experiments were conducted to optimize the extraction conditions in the reference describing SPME hop cones analysis (Kovačevič and Kač 2001). In the current work for SPME method $0.2 \mathrm{~g}$ of dry hop cones were taken. Dry hop cones were mixed with $2 \mathrm{ml}$ of distilled water into vial. SPME device (Supelco Inc., Bellefonte, PA, USA) with polydimethylsiloxane (PDMS) fiber of $100 \mu \mathrm{m}$ thickness was used for the determination of analytes. The headspace vials ( $5 \mathrm{ml}$ volume) were used for extractions. Sample preparation conditions were as follows: extraction time $45 \mathrm{~min}$, and extraction temperature $60{ }^{\circ} \mathrm{C}$. The temperature of SPME extraction was obtained by thermocirrculator Julabo F25 (Julabo Labortechnik GMbH, Seelbach, Germany). Thermal desorption of volatiles from the fiber was carried out in injector heated at $240{ }^{\circ} \mathrm{C}$, for $0.5 \mathrm{~min}$.

The calculation of the recovery rates for each sample preparation method were evaluated by the comparison of concentration of $\beta$-myrcene and $\beta$-caryophyllene in essential oils and extracts of hop cones and the concentration of these compounds in extracts obtained after the enrichment of hop cones by addition of $10 \mu \mathrm{l}$ of standards $(c=100.0 \mu \mathrm{g} / \mathrm{ml})$. Standards of $\beta$-myrcene and $\beta$-caryophyllene were supplied by Sigma Aldrich (Steinheim, Germany).

\section{Analytical Methods}

The obtained hop essential oils and extracts were analysed using GC-MS technique (AutoSystem XL and TurboMass mass spectrometer; Perkin Elmer, Shelton, CT, USA). One microliter of sample was injected using flow splitting 1:20. As carrier gas was helium with flow velocity of $0.8 \mathrm{ml} / \mathrm{min}$. An RTX-5 capillary column (Restek, Bellefonte, PA, USA) $(30 \mathrm{~m} \times 0.25 \mathrm{~mm}, 0.25 \mu \mathrm{m})$ was used. Oven temperature programming was as follows: initial $60{ }^{\circ} \mathrm{C}$ held for $3 \mathrm{~min}$, then ramped $2.0{ }^{\circ} \mathrm{C} / \mathrm{min}$ to $150{ }^{\circ} \mathrm{C}$, held for $5 \mathrm{~min}$, then ramped $10{ }^{\circ} \mathrm{C} / \mathrm{min}$ to $285{ }^{\circ} \mathrm{C}$ and held for $8 \mathrm{~min}$. Ion trap detection was carried out using electron impact ionisation. Following conditions were used: ion trap temperature $180{ }^{\circ} \mathrm{C}$, ionisation energy $70 \mathrm{eV}$, scan range: $30-250 \mathrm{~m} / \mathrm{z}$. The acquisition of chromatographic data was performed by means of TurboMass (Perkin Elmer) and mass spectra 
libraries NIST 2005 (Gatesburg, USA) and Wiley Registry of Mass Spectral Data, 6th Edition (John Wiley \& Sons, Palisade Corporation, Newfield, NY, USA).

Kovat's retention indices were determined using a mix of $n$-alkane standards from $\mathrm{C} 9$ to $\mathrm{C} 32$. In the case of temperature programmed chromatography, Kovat's retention indices are given using the following equation:

$I^{\mathrm{T}}=100 \frac{\left[t_{\mathrm{R} i}^{\mathrm{T}}-t_{\mathrm{R} z}^{\mathrm{T}}\right]}{\left[t_{\mathrm{R}(z+1)}^{\mathrm{T}}-t_{\mathrm{R} z}^{\mathrm{T}}\right]}$,

where $I^{\mathrm{T}}$ is the retention index for temperature programmed GC analysis, constant heating rate; $t_{\mathrm{R} i}^{\mathrm{T}}$ is the retention time of sample peak; $z$ is the carbon number of $n$-alkane eluting immediately before sample peak; $t_{\mathrm{R}(z+i)}{ }^{\mathrm{T}}$ is the retention time of $n$-alkanes peak eluting immediately after sample peak.

Chemometric Methods and Statistical Analysis

A multivariate analysis of the dataset representing distribution of several investigated compounds in the wild forms and domestic varieties of hops from the collection of Kaunas Botanical Garden of Vytautas Magnus University has been evaluated. The working hypothesis concerning various chemotypes of six wild hops and two domestic hop varieties was verified by analyses of variance and tests of significance at $P<0.05$. For significant effects from the ANOVA, means were separated using Tukey's HSD test $(P<0.05)$. For normality demand data of peaks area for each compound were log transformed and then analysed by one-way ANOVA with two replicates.

The matrix of data consists of eight types of hops (wild hop forms No. 43, 47, 49, 52, 56, 64, and hop varieties Alta and French Houblon precoce) as cases and 12 components as variables for grouping. The percentages of individual components were used for cluster analysis, based on $k$-means clustering. The means of each dimension were standardised within the hop types and, to obtain a meaningful structure of these types, the number of clusters was set to two. The results of clustering were analysed using the one-way ANOVA with a grouping variable (STATISTICA 8.0; StatSoft 2007).

\section{Results and Discussion}

Dry hop cones contain $0.5-2 \%$ of essential oil (Zanoli and Zavatti 2008). Four extraction methods (SPME, SFE, steam distillation as well as ASE) were used as a sample preparation method to obtain essential oil from hop cones. The comparison of extraction methods used for the selective separation of components from hop cones is presented in Table 1.
Table 1 Comparison of extraction methods used for the selective separation of components from hop cones

\begin{tabular}{llllll}
\hline No & Name & SPME & SFE & Steam distillation & ASE \\
\hline 1. & $\beta$-Myrcene & + & + & + & + \\
2. & Borneol & + & + & + & - \\
3. & $\alpha$-Copaene & - & + & + & - \\
4. & $\gamma$-Gurjunene & - & + & + & - \\
5. & $\beta$-Caryophyllene & + & + & + & + \\
6. & $\beta$-Cubebene & - & + & + & - \\
7. & $\alpha$-Bergamotene & - & + & + & - \\
8. & $\alpha$-Humulene & - & + & + & + \\
9. & $\beta$-Farnesene & - & + & + & - \\
10. & $\gamma$-Muurolene & + & + & + & - \\
11. & $\beta$-Selinene & - & + & + & + \\
12. & $\alpha$-Selinene & + & + & + & + \\
13. & $\alpha$-Farnesene & - & + & + & - \\
14. & $\gamma$-Cadinene & + & + & + & - \\
15. & $\delta$-Cadinene & - & + & + & - \\
16. & Eremophilene & - & + & + & + \\
17. & Eudesma-3,7-diene & - & + & + & + \\
18. & D-Longifolene & - & + & + & + \\
19. & Isohumulone & - & - & - & + \\
20. & Lupulon & - & - & - & + \\
\hline & & & & & + \\
\hline - & & + & + \\
\hline
\end{tabular}

$(+)$ detected compound, $(-)$ not detected compound

The results of GC-MS analyses confirm that the hop essential oil as well as extracts from hop cones are a complex mixture of various numbers of constituents. Number of constituents depends on the used extraction method. The most satisfactory results were obtained using the SFE and steam distillation of essential oils. It should be noted, that $\mathrm{CO}_{2}$ supercritical fluid as an extraction solvent was used at relatively low density $0.3 \mathrm{~g} / \mathrm{ml}$ (pressure 91 bar, temperature $50{ }^{\circ} \mathrm{C}$ ), which is most suitable for extraction of volatile compounds (Dzingelevičius et al. 2011). Additionally, to increase recovery of the essential oils, the trap temperature was programmed at $5{ }^{\circ} \mathrm{C}$. Both sample preparation methods SPME and ASE allowed to extract only a few compounds from hop cones. That reason, the use of these methods was insufficient and limited to six for SPME and ten compounds to ASE method, respectively. During multiple SFE method, the highest amount of essential oil is obtained in first step of extraction process (over $50 \%$ ). On the other hand, steam distillation is useful method for the preparation of hop essential oil. The recovery of volatile compounds from hop cones is highest by using of steam distillation. Results obtained using SFE, steam distillation and ASE methods for the separation of $\beta$-myrcene and $\beta$-caryophyllene are presented in Fig. 1.

The recovery using SFE can be increased by cooling down the trap and increasing the equilibration time, when other conditions of supercritical $\mathrm{CO}_{2}$ extraction are kept constant 
Fig. 1 Comparison of the efficiency of sample preparation methods including SPME, SFE, steam distillation and ASE; recovery data obtained for $\beta$ myrcene and $\beta$-caryophyllene

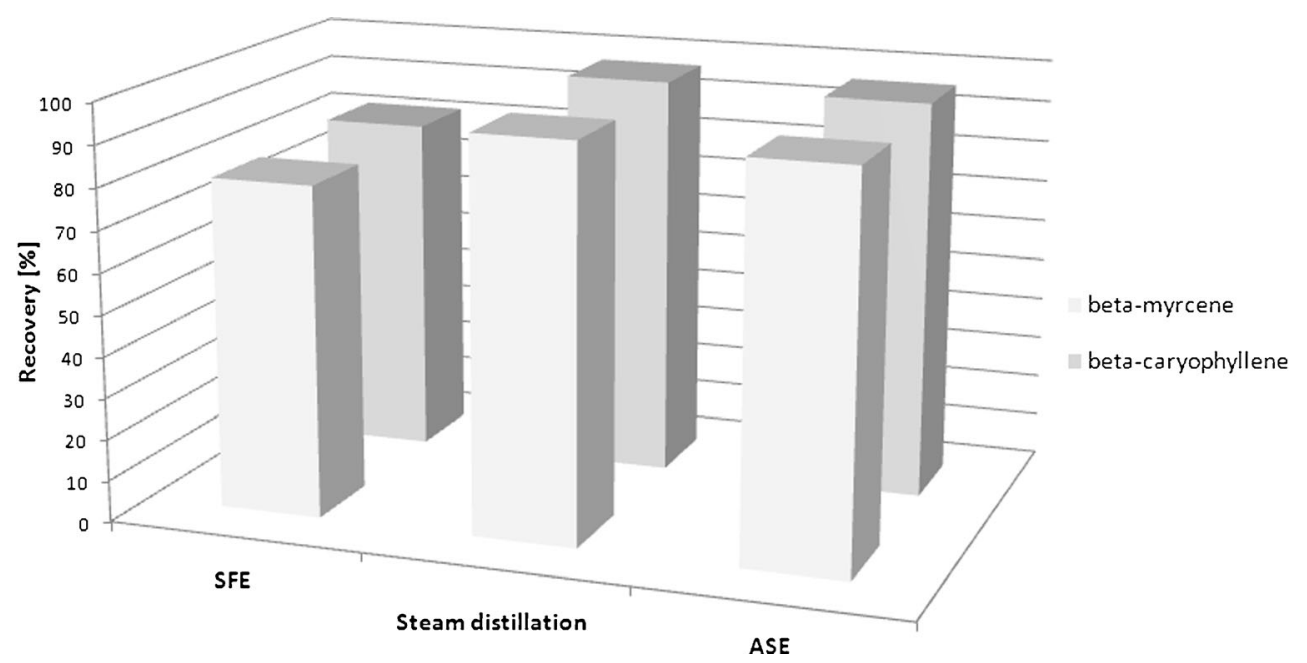

(Dzingelevičius et al. 2011). It should be noted however, that maximum recovery of essential oil using SFE sample preparation method was not a task of this study. For the determination and identification of components of essential oil of hops GCMS technique was used. The example chromatogram obtained for wild hop form essential oil supercritical $\mathrm{CO}_{2}$ extraction is presented in Fig. 2. This sample is characterised by a few number of volatiles. Over 200 peaks can be registered in GCMS chromatograms of hop essential oils. However, the group of major compounds includes: hydrocarbons, monoterpenes, and sesquiterpenes. Analysing the wild and domestic hops essential oils, obtained by supercritical $\mathrm{CO}_{2}$ extraction, the difference in the composition of each essential oil was detected. In particle, we observed changes in the concentrations of terpenes in hop essential oils. Some terpenes were detected only for a few samples of wild hop forms essential oils (eremophilene, eudesma-3,7-diene, D-longifolene).

The essential oil constituents were identified on the basis of their retentions, mass spectra according to mass spectra libraries and comparison with the literature data. Kovat's indices were used for identification of analysed compounds. The mix of $n$ alkanes standards from $\mathrm{C}_{9}$ to $\mathrm{C}_{32}$ were applied for the calculation of Kovat's retention indices. The most important volatile compounds are monoterpenes and sesquiterpenes, which together represent ca. $80 \%$ of total composition of essential oil. The retention times of compounds detected in extracts of hops essential oils and calculated retention indices are presented in Table 2.

The presence of volatile organic compounds, mainly terpenes (monoterpenes, e.g., myrcene, and sesquiterpenes, e.g., $\alpha$-humulene, $\beta$-caryophyllene, and $\beta$-farnesene) and nonvolatile bitter acids including $\alpha$-acids (e.g., humulone, cohumulone and adhumulone) and $\beta$-acids (lupulone, colupulone and adlupulone) affect the biological activity of hop products. These bitter acids have bacteriostatic properties; they also are responsible for the bitter taste of beer, whereas essential oils provide characteristic flavour to the product. Nevertheless, bitter acids are non-volatile compounds and can be separated using high performance liquid chromatography or capillary electrophoresis (Stanius et al. 2005; Kornyšova et al. 2009). Due to non-volatility, the composition of bitter acids was not an object of this study.

For each sample, the sum of the areas of selected 11 peaks was calculated. Among these compounds $\beta$-myrcene, $\alpha$ copaene, $\beta$-caryophyllene, $\beta$-cubebene, $\alpha$-bergamotene, $\alpha$ -
Fig. 2 Typical GC/MS

chromatogram of hop essential oil obtained for selected sample, where: $1 \beta$-myrcene, 2 borneol, 3 copaene, $4 \gamma$-gurjunene, $5 \beta$ caryophyllene, $6 \beta$-cubebene, 7 $\alpha$-bergamotene, $8 \alpha$-humulene, 9 $\beta$-farnesene, $10 \gamma$-muurolene, 11 $\beta$-selinene, $12 \alpha$-selinene, $13 \alpha$ farnesene, $14 \gamma$-cadinene, $15 \delta$ cadinene, 16 eremophilene, 17 eudesma-3,7-diene, $18 \mathrm{D}$ longifolene

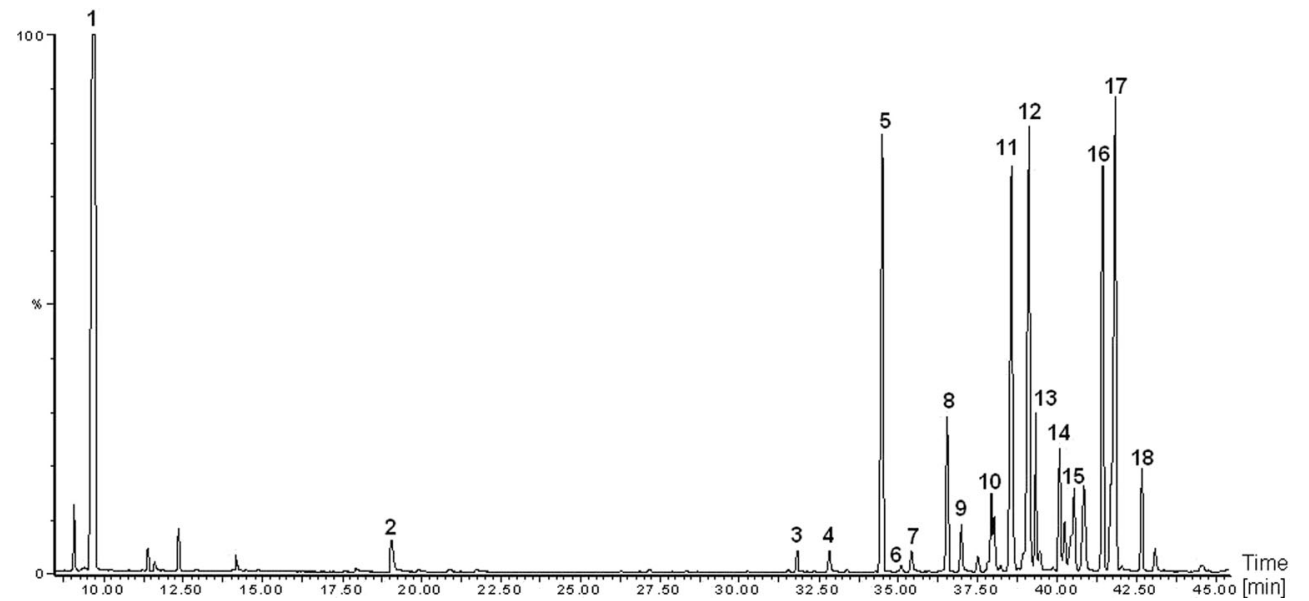


Table 2 Retention parameters $\left(t_{\mathrm{R}}\right.$, calculated retention index, and Kovats retention index) and $\mathrm{m} / \mathrm{z}$ value of molecular ion obtained by GC-MS for selected compounds from hop essential oil

\begin{tabular}{lllll}
\hline Compound & $t_{\mathrm{R}}(\mathrm{min})$ & $m / z$ & Ret. index & Kovats retention index from the literature \\
\hline Myrcene & 9.73 & 136 & 995 & 995 (Shellie et al. 2002) \\
Borneol & 19.06 & 154 & 1,169 & 1,167 (Mondello et al. 2002) \\
$\alpha$-Copaene & 31.81 & 204 & 1,374 & 1,366 (Kovačevič and Kač 2002) \\
$\gamma$-Gurjunene & 32.83 & 204 & 1,391 & - \\
$\beta$-Caryophyllene & 34.48 & 204 & 1,418 & 1,416 (Mondello et al. 2002) \\
$\beta$-Cubebene & 35.08 & 204 & 1,428 & - \\
$\alpha$-Bergamotene & 35.43 & 204 & 1,436 & 1,430 (Kovačevič and Kač 2002) \\
$\alpha$-Humulene & 36.53 & 204 & 1,453 & 1,459 (Mondello et al. 2002) \\
$\beta$-Farnesene & 36.98 & 204 & 1,458 & 1,461 (Shellie et al. 2002) \\
$\gamma$-Muurolene & 38.04 & 204 & 1,477 & 1,468 (Kovačevič and Kač 2002) \\
$\beta$-Selinene & 38.54 & 204 & 1,486 & 1,487 (Mondello et al. 2002) \\
$\alpha$-Selinene & 39.10 & 204 & 1,495 & 1,483 (Kovačevič and Kač 2002) \\
$\alpha$-Farnesene & 39.32 & 204 & 1,499 & - \\
$\gamma$-Cadinene & 40.09 & 204 & 1,513 & 1,503 (Kovačevič and Kač 2002) \\
$\delta$-Cadinene & 40.85 & 204 & 1,526 & 1,529 (Mondello et al. 2002) \\
Eremophilene & 41.45 & 204 & 1,536 & - \\
Eudesma-3,7-diene & 41.82 & 204 & 1,542 & - \\
D-Longifolene & 42.63 & 204 & 1,556 & - \\
\hline & & & &
\end{tabular}

humulene, $\beta$-farnesene, $\gamma$-muurolene, $\beta$-selinene, $\gamma$ cadinene, and $\sigma$-cadinene were identified. Content fractions for each compound were defined as the ratio between the peak area for that compound and the sum of all selected 11 peaks areas in that sample. The quantitative analysis in hop extracts was performed for selected compounds by the expression of results as peak area \% was applied. In this cause, if not all response factors can be determined, the following expression for the percentage of analyte a can be used, which assumes all response factors to be unity (2):

$\%$ analyte $=\frac{A_{\mathrm{a}}}{\sum A_{i}} \times 100$,

where $\sum A_{i}$ is the sum of all the peak areas in the chromatogram.

For 1 year harvest, the range of percentage of main components of hop essential oils obtained from wild hop varieties was evaluated as follows for $\beta$-myrcene from $6.04 \%$ to $30.88 \%, \alpha$-copaene from $0.30 \%$ to $0.49 \%, \beta$ caryophyllene from $7.67 \%$ to $13.98 \%, \beta$-cubebene from $0.13 \%$ to $1.00 \%, \alpha$-bergamotene from $0.31 \%$ to $29.04 \%$,

Table 3 Three extractions of selected sample, calculated standard deviations, standard errors

\begin{tabular}{llll}
\hline & Chr.56A1 & Chr.56A2 & Chr.56A3 \\
\hline Standard deviation & $1.671 \%$ & $1.650 \%$ & $1.564 \%$ \\
Number of peaks & 538 & 543 & 532 \\
Standard error & $0.072 \%$ & $0.071 \%$ & $0.068 \%$ \\
\hline
\end{tabular}

$\alpha$-humulene from $3.08 \%$ to $31.51 \%, \beta$-farnesene from $0.90 \%$ to $14.78 \%, \gamma$-muurolene from $1.04 \%$ to $2.46 \%, \beta$ selinene from $1.01 \%$ to $8.36 \%, \gamma$-cadinene from $1.04 \%$ to $2.07 \%, \sigma$-cadinene from $1.22 \%$ to $2.59 \%$. Moreover, the range of percentage of main components of hop essential oils obtained from domestic hops was also evaluated. There were obtained for $\beta$-myrcene from $14.48 \%$ to $29.34 \%, \alpha$-copaene from $0.36 \%$ to $0.39 \%, \beta$-caryophyllene from $9.17 \%$ to $9.98 \%, \beta$-cubebene from $0.35 \%$ to $0.37 \%, \alpha$-bergamotene from $0.02 \%$ to $1.67 \%, \alpha$-humulene from $11.02 \%$ to $15.82 \%, \beta$-farnesene from $0.64 \%$ to $18.30 \%, \gamma$-muurolene from $0.72 \%$ to $1.23 \%, \beta$-selinene from $0.50 \%$ to $1.38 \%, \gamma$ cadinene from $0.82 \%$ to $1.27 \%, \sigma$-cadinene from $1.37 \%$ to $2.03 \%$. In addition the detection limits (LODs) for $\beta$-myrcene and $\beta$-caryophyllene defined as a signal/noise ratio of 3 were evaluated. The LOD value for $\beta$-myrcene was $0.002 \mu \mathrm{g} / \mathrm{ml}$, and for $\beta$-caryophyllene it was $0.005 \mu \mathrm{g} / \mathrm{ml}$.

The most important compounds responsible for the special flavour of hop essential oils are myrcene, $\alpha$-humulene, $\beta$ caryophyllene, and $\beta$-farnesene. The concentration of $\beta$ myrcene, $\alpha$-humulene in hop essential oils obtained from cones two times harvests is much higher than other volatile

Table 4 Three injections of the same extract, calculated standard deviations, standard errors

\begin{tabular}{llll}
\hline & Chr.56A1 & Chr.56A2 & Chr.56A3 \\
\hline Standard deviation & $1.591 \%$ & $1.439 \%$ & $1.613 \%$ \\
Number of peaks & 481 & 491 & 484 \\
Standard error & $0.073 \%$ & $0.065 \%$ & $0.073 \%$ \\
\hline
\end{tabular}




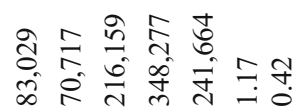

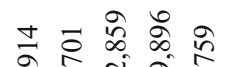

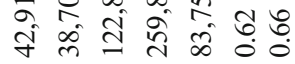

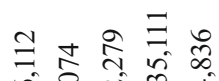

बूँ

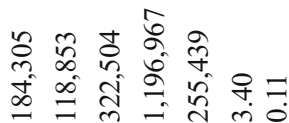

กิ่

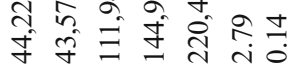

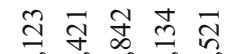

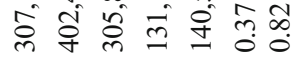

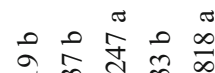

$\exists \tilde{i}$ त

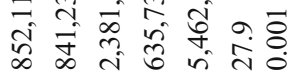

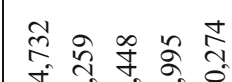

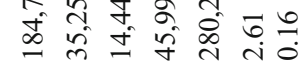

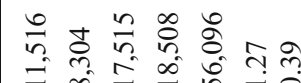

เ

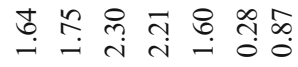

政

:

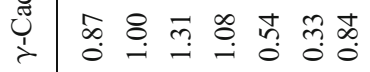

일

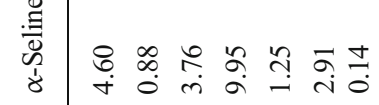

:

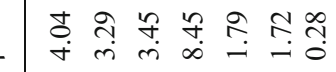

(1)

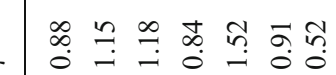

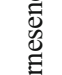

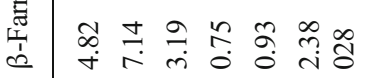

\%

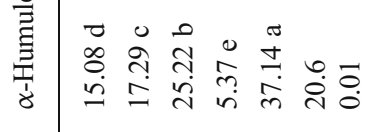

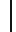

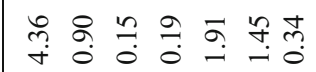

$=\infty-\infty i$

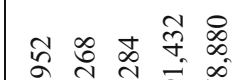

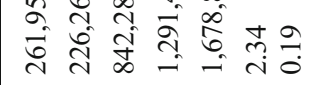

융류월 율

ते

$\infty \underset{0}{2} \approx \tilde{b}_{0}$

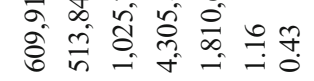

สุ่ $\frac{\pi}{0} \stackrel{\infty}{0}$ :

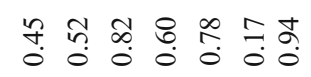


Table 7 Results of clustering of components based on mean value of \% contribution for eight hops

\begin{tabular}{|c|c|c|c|c|c|c|c|c|c|c|}
\hline Hop & $\begin{array}{l}\text { Mean for group } 1 \\
\beta \text {-Myrcene, } \alpha \text {-humulene }\end{array}$ & $\begin{array}{l}\text { Mean for group } 2 \\
\alpha \text {-Copaene, } \beta \text {-caryophyllene, } \\
\beta \text {-cubebene, } \alpha \text {-bergamotene, } \\
\beta \text {-farnesene, } \gamma \text {-muurolene, } \\
\beta \text {-selinene, } \alpha \text {-selinene, } \\
\gamma \text {-cadinene, } \sigma \text {-cadinene }\end{array}$ & $\begin{array}{l}\text { SS } \\
\text { Effect }\end{array}$ & $\begin{array}{l}d f \\
\text { Effect }\end{array}$ & $\begin{array}{l}\text { MS } \\
\text { Effect }\end{array}$ & $\begin{array}{l}\text { SS } \\
\text { Error }\end{array}$ & $\begin{array}{l}d f \\
\text { Error }\end{array}$ & $\begin{array}{l}\text { MS } \\
\text { Error }\end{array}$ & $F$ & $P$ \\
\hline No. 43 & 15.4 & 5.14 & 187.1 & 1 & 187.1 & 697.0 & 9 & 77.4 & 2.41 & 0.154 \\
\hline No. 47 & 21.5 & 340 & 533.5 & 1 & 533.5 & 259.3 & 9 & 28.8 & 18.5 & 0.001 \\
\hline No. 49 & 18.8 & 2.73 & 421.3 & 1 & 421.3 & 432.4 & 9 & 48.0 & 8.76 & 0.015 \\
\hline No. 52 & 17.0 & 2.66 & 335.4 & 1 & 335.4 & 482.3 & 9 & 53.5 & 6.25 & 0.033 \\
\hline No. 56 & 23.7 & 3.54 & 661.1 & 1 & 661.1 & 218.7 & 9 & 24.3 & 27.2 & 0.000 \\
\hline No. 64 & 17.0 & 2.73 & 332.1 & 1 & 332.1 & 359.2 & 9 & 39.9 & 8.31 & 0.018 \\
\hline Houblon precoce & 20.2 & 3.83 & 434.7 & 1 & 434.7 & 461.8 & 9 & 51.3 & 8.47 & 0.017 \\
\hline Alta & 15.2 & 1.65 & 298.3 & 1 & 298.3 & 66.18 & 9 & 7.35 & 40.6 & 0.000 \\
\hline
\end{tabular}

The analysis of variance with grouping variable results

organic compounds. On the other hand, $\beta$-farnesene $(7,11$ dimethyl-3-methylene-1,6,10-dodecatriene) naturally occurring as one isomer, is characterised as insect semiochemical and takes a role as an alarm pheromone, also as a natural insect repellent. In analysed essential oils, $\beta$-farnesene is a constituent in higher (more than four times as mean) quantity of hop essential oils obtained from cones from second year harvest than from cones harvested in the first year. Since the plants are growing at identic edaphic conditions, the differences in the metabolites accumulation can be due to variation of hydrothermal and related parameters during the first and second harvest years. The ambient conditions during the vegetation could be expressed by Selyaninov's hydrothermal coefficient (Selyaninov 1928):

$$
\mathrm{HTC}=\sum Q / 0.1 \sum T
$$

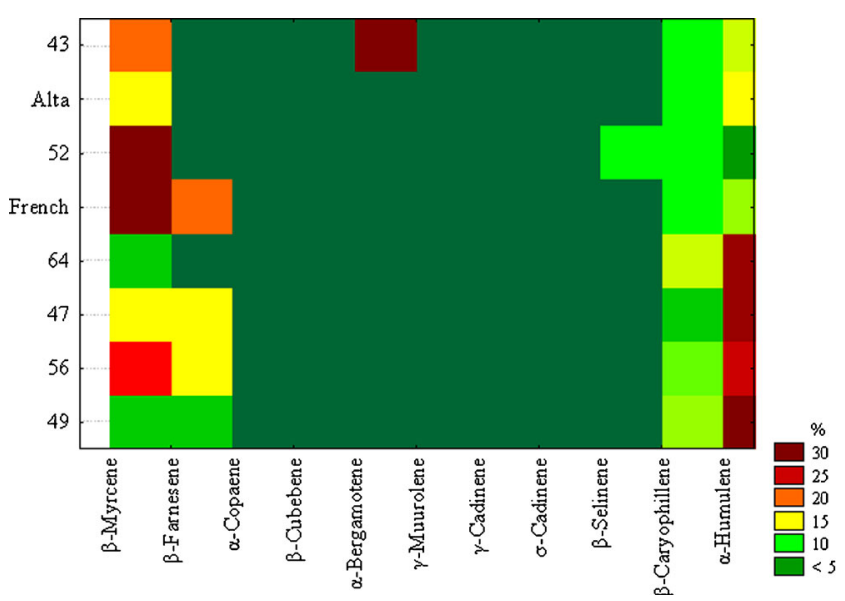

Fig. 3 Clustering of data obtained for examined hop varieties and essential oils components where $\sum \mathrm{Q}$ is a precipitations sum $(\mathrm{mm})$ during the test period, when the average daily air temperature is higher than $10{ }^{\circ} \mathrm{C}$, and $\sum T$ is the sum of temperatures for the same time period.

Both first and second harvest years show similar HTC during May -September (the vegetation period of hops) 1.75 and 1.7 , correspondingly, which were characterized as wet. Humidity coefficient $K$ proposed by Dirse and Taparauskiene (2010) differentiated the harvest years, i.e., first harvest year was wet $K=0.93$ and the second harvest year was also the same, but $K=0.8$. A Closer look at the vegetation periods shows that during June of the second harvest year precipitation was very low, only $18 \mathrm{~mm}$ and the coefficient of humidity in June was $K=0.56$, which indicates a drought. All the vegetation months of the first harvest year were moderately humid or wet. The drought in the first harvest year can be a reason of the metabolic response-ca. 4-fold lower content of $\beta$-farnesene as average in investigated hops, although further investigations are needed to confirm this observation.

One of the most important investigations was identification of repeatability of results. Appropriate values of standard deviations and standard errors for extraction and analytical methods are presented in Tables 3 and 4. The obtained total peak area was taken into consideration.

Among 12 compounds identified in hop essential oils the only significant difference between wild hops forms was obtained for $\alpha$-humulene elicited the greater peaks at wild hops forms No. 49 and 64 (Table 5). The percents of individual components were transformed by square root to obtain normal distribution and then were analysed by the same model of analysis of variance. 
Fig. 4 Dendrogram of CA according to Ward's method obtained analysing essential oils of different forms of wild hops and selected domestic varieties (Alta and French delicacies)

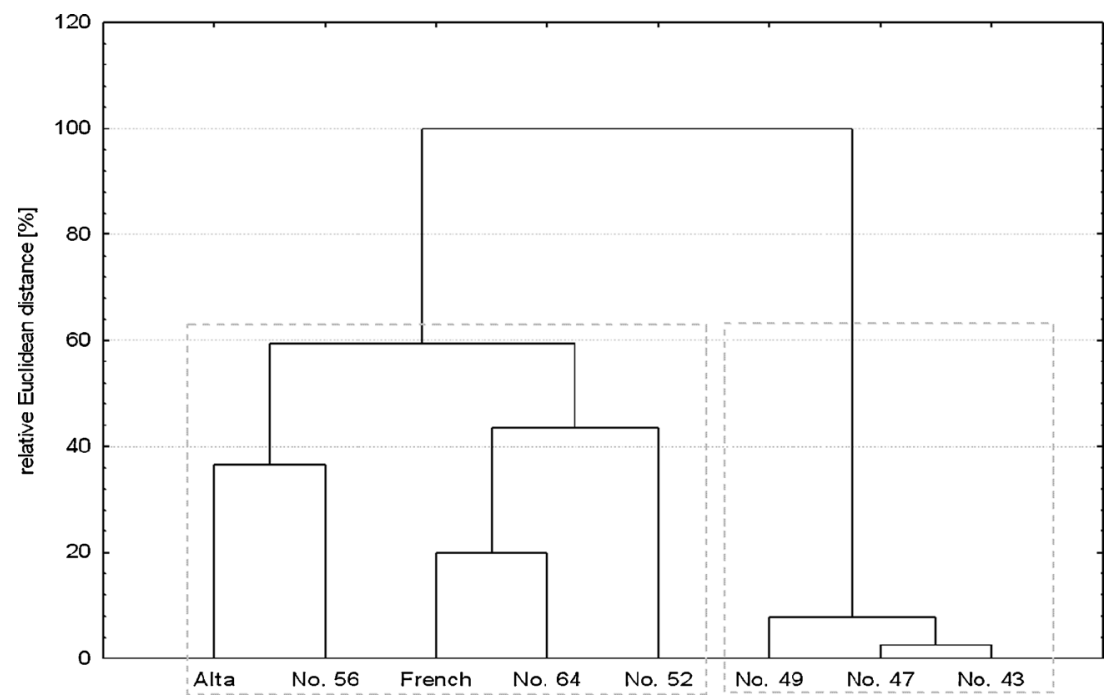

The ANOVA results for components contribution altered the inference of peaks area into two additional issues. First, the wild forms of hop differed with contribution of $\alpha$-humulene and also with $\beta$-caryophyllene (Table 6). Second, essential oil pattern described by peak area became more intensive when data had been calculated as percentages of their total amount. It was obvious that some components prevailed over others. These prompted authors to study the structure of all components overall hop types using classification method based on cluster analysis.

Two components - $\beta$-myrcene and $\alpha$-humulene - were arranged into the first group through their similar, great contribution (15.2-23.7\%) in total amount of all volatiles. Another nine components were grouped together giving the mean percentages of contribution from $1.56 \%$ to $5.14 \%$ (Table 7 ).

For seven hop types, this grouping was significantly confirmed by ANOVA at $P<0.05$. Simultaneous grouping of 11 components and eight hop types (Fig. 3) extended the sense of essential oil pattern. When $\beta$-myrcene did not prevail in total amount of essential oils, the dominant component was $\alpha$ humulene as in the case of wild hop forms Nos. 47, 49, 56, 64 and variety Alta. Opposite reaction was obtained for hop wild forms Nos. 43, 52 and French hop variety Houblon precoce.

Similarities between investigated hope types were evaluated by chemometric methods using chromatographic data of 11 compounds for each sample. Oil essential pattern described by peak surfaces were processed using two classification methods: cluster analysis (CA), which was used to distinguish characteristic components of hop forms; and dendrogram, which was charted to represent relations between different hop forms (Fig. 4). Two groups of samples can be discriminated. The first one consists of the samples no.: 43, 47 and 49 and is characterised by small differences within this group. The second one contains the rest of samples. Dissimilarities between samples in this group are rather high; therefore, subdivision of it is possible on $50 \%$ of maximal relative Euclidean distance and for such reason the samples cannot be defined as similar.

\section{Conclusions}

In conclusion, it should be mentioned that multivariate analysis of the dataset representing distribution of several investigated compounds in the wild forms and domestic varieties of hops from the collection of Kaunas Botanical Garden of Vytautas Magnus University has been presented. Two methods of sample preparation - SFE and steam distillation — have been successfully adopted for the preaparation of hop essential oils. The results indicate samples having similar composition of oils and the samples with increased level of particular compound. Changes in the concentration of monoterpenes and sesquiterpenes in hop essential oils distinguish wild forms of hops and two domestic hop varieties studied.

The special flavour of hop essential oil is combined by the presence of terpenes, especially monoterpenes (myrcene) and sesquiterpenes like $\alpha$-humulene, $\beta$-caryophyllene, and $\beta-$ farnesene. One of them, $\beta$-myrcene, is an important part of the essential oils of various plants, most notably hops. It is considered the headlining feature of the green hop aroma. It has an odour which is described by chemists as herbaceous, resinous, green, balsamic, fresh hops.

The performed analysis can be an easy-to-use tool evaluating different chemotypes of hops. Further investigation of other hop samples, however, is necessary for the classification of the essential oils, whether they exhibit systemic changes from year to year. 
Acknowledgements This work was supported by Vytautas Magnus University research fund $\mathrm{F}-08-03$.

Compliance with ethics requirements This article does not contain any studies with human or animal subjects.

Conflict of Interest Magdalena Ligor declares that she has no conflict of interest. Mantas Stankevičius declares that he has no conflict of interest. Anna Wenda-Piesik declares that she has no conflict of interest. Kęstutis Obelevičius declares that he has no conflict of interest. Ona Ragažinskienè declares that she has no conflict of interest. Žydrūnas Stanius declares that he has no conflict of interest. Audrius Maruška declares that he has no conflict of interest. Bogusław Buszewski declares that she has no conflict of interest.

Open Access This article is distributed under the terms of the Creative Commons Attribution License which permits any use, distribution, and reproduction in any medium, provided the original author(s) and the source are credited.

\section{References}

Bernotiene G, Nivinskiene O, Butkiene R, Mockute D (2004) Chemical composition of essential oils of hops (Humulus lupulus L.) growing wild in Aukštaitija. Chemija 15:31-36

Bro R, Van den Berg F, Thybo A, Anderseny CM, Jørgensen BM, Andersen H (2002) Multivariate data analysis as a tool in advanced quality monitoring in the food production chain. Trends in Food Scien Technol 13:235-244

Buszewski B, Kawka S, Suprynowicz Z, Wolski T (1993a) Simultaneous isolation of rutin and esculin from plant material and drugs using solid-phase extraction. J Pharm Biomed Anal 11(3):211-215

Buszewski B, Kawka S, Wolski T (1993b) Simultaneous isolation and determination of esculin and rutin in natural materials using SPE and HPLC. Chromatographia 35(5/6):311-316

Čulík J, Jurková M, Horák T, Čejka P, Kellner V, Dvořák J, Karásek P, Roth M (2009) Extraction of bitter acids from hops and hop products using pressurized solvent extraction (PSE). J Inst Brew 115(3):220 225

Dirsė A, Taparauskienè L (2010) Humidity fluctuations in plant vegetation periods and comparison of its assesment methods. Agiculture Sci (17)1-2: 9-17

Dzingelevičius N, Maruška A, Ragažinskienė O, Obelevičius K (2011) Optimization of hops essential oil extraction by means of supercritical $\mathrm{CO}_{2}$. Biologija (57)2:63-69

Eri S, Khoo BK, Lech J, Hartman TG (2000) Thermal desorption-gaschromatography and gas chromatography-mass spectrometry profiling of hop (Humulus lupulus L.). J Agr Food Chem 48:1140 1149

Howard GA (1970) Institute of brewing, analysis committee: the determination of hop oil. J Inst Brew 76(4):381

Katsiotis ST, Langczaal CR, Scheffer JJC (1990) Composition of the essential oils from leaves of various Humulus lupulus L. cultivars. Flav Frag J 5:97-100

Kornyšova $O$, Stanius Ž, Obelevičius K, Ragažinskienė O, Skrzydlewska E, Maruška A (2009) Capillary zone electrophoresis method for determination of bitter acids ( $\alpha$ - and $\beta$-) in hop (Humulus lupulus L.) cone extracts. Adv Med Sci 54(1):41-46
Kovačevič M, Kač M (2001) Solid-phase microextraction of hop volatiles. Potential use for determination and verification of hop varieties. J Chromatogr A 918:159-167

Kovačevič M, Kač M (2002) Determination and verification of hop varieties by analysis of essential oils. Food Chem 77:489-494

Kowalkowski T, Zbytniewski R, Szpejna J, Buszewski B (2006) Application of chemometrics in river water classification. Water Res 40(4):744-752

Langezaal CR, Chandra A, Katsiotis ST, Scheffer JJC, De Haan AB (1990) Analysis of supercritical carbon dioxide extracts from cones and leaves of a Humulus lupulus L. cultivar. J Sci Food Agri 53:455-463

Ligor M, Buszewski B (1999) Determination of methol and methone in food and pharmaceutical product by SPME/GC. J Chromatogr A $847: 161-169$

Ligor M, Kornyšova O, Maruška A, Buszewski B (2008) Determination of flavonoids in tea and Rooibos extracts by TLC and HPLC. J Planar Chromatogr 21(5):355-360

Ligor M, Szumski M, Buszewski B (2000) Isolation and determination of flavor and fragrance components from natural products by SPME/ GC and SFE/GC methods. International Lab 30(1):22-25

Malizia RA, Molli JS, Cardell DA, Grau RJA (1999) Essential oil of hop cones (Humulus lupulus L.). J Essent Oil Res 11:13-15

Mockute D, Bernotiene G, Nivinskiene O, Butkiene R (2008) Variability of volatiles of wild Hops (Humulus lupulus L.) growing in Eastern Lithuania. J Essent Oil Res 20(2):96-101

Mondello L, Zappia G, Cotroneo A, Bonaccorsi I, Chowdhury JU, Yusuf M, Dugo G (2002) Studies on the essential oil-bearing plants of Bangladesh: Part VIII. Composition of some Ocimum oils O. basilicum L. var. purpurascens; O. sanctum L. green; O. sanctum L. purple; O. americanum L., citral type; O. americanum L., camphor type. Flav Fragr J 17:335-340

Munck L, Nørgaard L, Engelsen SB, Bro R, Andersson CA (1998) Chemometrics in food science - a demonstration of the feasibility of a highly exploratory, inductive evaluation strategy of fundamental scientific significance. Chemom Intell Lab Syst 44:31-60

Obelevičius K (2003) Meteorologinių sąlygų itaka paprastojo apynio (Humulus lupulus) veisliu derliui ir jo kokybei. Botanica Lithuanica Suppl 5:87-95 (in Lithuanian)

Ravenchon E (1997) Supercritical fluid extraction and fractionation of essential oils and related products. J Supercritical Fluids 10:1-37

Sägesser M, Deinzer M (1996) HPLC-ion spray-tandem mass spectrometry of flavonol glycosides in hops. J Amer Soc Brew Chem 54: 129-134

Selyaninov GT (1928) On agricultural climate valuation. Proc Agric Meteor 20:165-177 (in Russian)

Shellie R, Mondello L, Marriott P, Dugo G (2002) Characterisation of lavender essential oils by using gas chromatography-mass spectrometry with correlation of linear retention indices and comparison with comprehensive two-dimensional gas chromatography. J Chromatogr A 970:225-234

Stanius Ž, Obelevičius K, Kornyšova O, Maruška A, Ragažinskienė O (2005) Capillary electrophoresis method for determination of bitter ( $\alpha$ - and $\beta$-) acids in Humulus lupulus L. Lithuanian varieties Biologija 3:81-84

Stankevičius M, Ligor M, Obelevičius K, Ragažinskienè O, Maruška A, Buszewski B (2007) Phytochemical analysis of hop essential oils: determination of ecotypes and phenotypes using gas chromatography and mass spectrometry technique. Proceedings of International conference The Vital Nature Sign, pp. 92-94

Zanoli P, Zavatti M (2008) Pharmacognostic and pharmacological profile of Humulus lupulus L. J Ethnopharmacology 116:383-396 